\title{
Pharmacodynamic Properties of Sodium Cellulose Sulfate
}

\author{
Kenji Kamide, Kunihiko OKaJIMA, Toshihiko Matsui, \\ and Hidehiko KOBAYASHI* \\ Textile Research Laboratory, Asahi Chemical Industry Co., Ltd., \\ 11-7 Hacchonawate, Takatsuki, Osaka 569, Japan \\ *Development and Technology Administration, \\ Asahi Chemical Industry Co., Ltd., \\ 1-1-2 Yurakucho, Chiyoda-ku, Tokyo 100, Japan
}

(Received December 22, 1983)

\begin{abstract}
An attempt was made to evaluate certain pharmacodynamic properties of sodium cellulose sulfate ( $\mathrm{NaCS}$ ) using rats, rabbits, dogs, and cats. Two $\mathrm{NaCS}$ samples, whose molecular characteristics, anticoagulant activity and acute toxicity were determined in our previous paper [Polym. J., 15, 309 (1983)], were used. A pyrogen test was made, and the changes in blood pressure, heart rate and respiration, and the effect of histamine antagonists pre-treatment were examined. The following was confirmed: 1) An intravenous administration of $1 \mathrm{mg} \mathrm{kg}^{-1}$ of the two $\mathrm{NaCS}$ to dogs and cats had no effect on the cardiac function of these animals. 2) At a dose level of $10 \mathrm{mg} \mathrm{kg}^{-1}$ of the two $\mathrm{NaCS}$ to dogs, an abrupt blood pressure depression amounting to $40-$ $100 \mathrm{mmHg}$ in the average blood pressure was observed, and found to be proportional to the reciprocal of the acute toxicity $\left(\mathrm{LD}_{50}\right)$. This finding indicated that the blood pressure depression by $\mathrm{NaCS}$ administration is dependent on the molecular weight and the distribution of the substituent $\left(\left\langle\mathrm{f}_{2}\right\rangle\right\rangle+\left\langle\left\langle\mathrm{f}_{3}\right\rangle\right)$ in NaCS. 3) NaCS administration to a cat induced an abrupt rise in blood pressure, in contrast to the case of the dog. 4) NaCS administration was accompanied by tachyphylaxis. 5) The liberation of histamine and acetylcholine as the cause of these cardiac changes by $\mathrm{NaCS}$ administration was ruled out experimentally, and the liberation of bradykinin was considered the most probable cause.
\end{abstract}

KEY WORDS Sodium Cellulose Sulfate / Pharmacodynamic Properties / Molecular Characteristics / Blood Pressure Depression /

Sodium cellulose sulfate $(\mathrm{NaCS})$ has as strong anticoagulant activity ${ }^{1-10}$ as heparin and condroitin sulfate. Its pharmacodynamic properties were first studied by Rothschild and his coworkers. ${ }^{11-13}$ Their findings were as follows: 1) $\mathrm{NaCS}$ depletes bradykinin from blood plasmas of rat, guinia pig and man. 2) Administration of $\mathrm{NaCS}$ to rat results in a depression of blood pressure with tachyphylaxis, the reduction of kininogen in plasma and moderate leucocytosis. 3) The blood pressure depressing activity of $\mathrm{NaCS}$ against rat can be inhibited by pre-treatment with trypsin from soyabean, but not with a histamine antagonist (mepyramine). In their papers, the method of synthesis (i.e., pyridine/ chlorosulfonic acid method) as well as these pharmacodynamic properties were described very briefly but the work was restricted to rat and no data on the molecular characteristics of $\mathrm{NaCS}$ were given. Therefore, it is of prime importance to confirm whether their finding can apply to other animals, using samples of $\mathrm{NaCS}$ whose molecular characteristics are definitely known.

Recently, Kamide and his coworkers studied the dilute solution properties of $\mathrm{NaCS},{ }^{14}$ the distribution of the sulfate group in the glucopyranose ring, ${ }^{15}$ and the roles of molecular characteristics of $\mathrm{NaCS}$ in its anticoagulant activity and acute toxicity. ${ }^{10}$ The anticoagulant activity of $\mathrm{NaCS}$ 
was shown to be proportional to $\left\langle\mathrm{f}_{2}\right\rangle+$ $\left\langle\mathrm{f}_{3}\right\rangle$, where $\left\langle\mathrm{f}_{2}\right\rangle$ and $\left.\left\langle\mathrm{f}_{3}\right\rangle\right\rangle$ denote the probabilities of finding a substituent at the $\mathrm{C}_{2}$ and $\mathrm{C}_{3}$ positions of a glucopyranose unit, respectively, and almost independent of the number-average molecular weight $\left(M_{n}\right)$ and the acute toxicity $\left(\mathrm{LD}_{50}\right.$ : vein injection to rat) to be a function of $\left\langle\mathrm{f}_{2}\right\rangle+\left\langle\left\langle\mathrm{f}_{3}\right\rangle\right.$ and a convex function of $M_{n}$ when compared at the same $\left\langle\mathrm{f}_{2}\right\rangle+\left\langle\mathrm{f}_{3}\right\rangle$, and the method synthesizing NaCS to influence $\left\langle\mathrm{f}_{k}\right\rangle(k=2,3$ and 6$)$.

In this study, as an extension of our previous work, ${ }^{10}$ we attempted to elucidate the pharmacodynamic properties of $\mathrm{NaCS}$ using dogs and cats.

\section{EXPERIMENTAL}

\section{Sodium Cellulose Sulfate (NaCS)}

Two NaCS samples, CS-4 and CS-16, prepared previously ${ }^{10}$ with a dimethylformamide/ sulfur trioxide complex as a sulfating reagent, were used. Their molecular characteristics, anticoagulant activity $\left(\chi\left(\mathrm{IU} \mathrm{mg}^{-1}\right)\right)$, and acute toxicity $\left(\mathrm{LD}_{50 \text {, rat }}\left(\mathrm{mg} \mathrm{kg}^{-1}\right)\right)$ are listed in Table I. In the table, $\langle\mathrm{F}\rangle$ denotes the total degree of substitution determined by the NMR method, ${ }^{15}$ and $M_{n}$, the number-average molecular weight determined by membrane osmometry. $\chi$ was determined by modifying the procedure described in the Japanese Pharmacopoeia No. $\mathrm{C} 1235-\mathrm{C} 1242 .{ }^{10} \mathrm{LD}_{50}$ is the value for rat determined by vein administration. ${ }^{10}$ The $\mathrm{NaCS}$ samples were dissolved in physiological saline to give 0.1 and $1.0 \mathrm{~g} \mathrm{dl}^{-1}$ solutions.

\section{Pyrogene Test}

Following the Commentary of Japanese Pharmacopoeia, three rabbits with body weights of $1.5-2.7 \mathrm{~kg}$ were subjected to this test. $20 \mathrm{mg} \mathrm{kg}^{-1}$-rabbit of $\mathrm{NaCS}$ were intravenously administered to each rabbit. The body temperature of the rabbit before injection was measured at $1 \mathrm{~h}$ intervals for $3 \mathrm{~h}$. When the temperatures at the second and third measurements were nearly equal, the temperature at the third measurement was taken as the reference temperature. The body temperature of the rabbit after injection of $\mathrm{NaCS}$ was measured at $1 \mathrm{~h}$ intervals for $5 \mathrm{~h}$, and the difference between the maximum and reference temperatures was recorded. In all cases, the injection of CS-4 and CS-16 did not cause a rise in body temperature exceeding $0.6^{\circ} \mathrm{C}$ and also the sum of the temperature rises for three rabbits did not exceed $1.4^{\circ} \mathrm{C}$.

\section{Effect of NaCS Injections on Rats}

While estimating the $\mathrm{LD}_{50}$ of $\mathrm{NaCS}$ administered to rats, we also observed signs of torture and excitation appeared on rats.

\section{Changes in Blood Pressure, Heart Rate and Respiration}

A male and a female dog each with a body weight of $10-13 \mathrm{~kg}$ and a male cat with a body weight of $2.9 \mathrm{~kg}$ were used. These animals were anesthetized by sodium penta balbital (35 $\mathrm{mg} \mathrm{kg}^{-1}$ ) and fixed in the supine position. The anesthetizing agent was administered to the vein of the dogs and the peritoneal cavity of the cat. The administration was carried out by inserting a polyethylene tube

Table I. Molecular characteristics and physiological properties of sodium cellulose sulfate

\begin{tabular}{|c|c|c|c|c|c|c|c|}
\hline \multirow{2}{*}{ Sample } & \multirow{2}{*}{$M_{n} \times 10^{-4}$} & \multirow{2}{*}{$《 F 》$} & \multirow{2}{*}{$\left\langle\mathrm{f}_{2}\right\rangle$} & \multirow{2}{*}{$\left\langle\mathrm{f}_{3}\right\rangle$} & \multirow{2}{*}{$\left\langle\mathrm{f}_{6}\right\rangle$} & $\chi$ & \multirow{2}{*}{$\frac{\mathrm{LD}_{50}}{\mathrm{mg} \mathrm{kg}^{-1}}$} \\
\hline & & & & & & $\mathrm{IU} \mathrm{mg}^{-1}$ & \\
\hline CS-4 & 6.65 & 2.46 & 1.00 & 0.74 & 0.72 & $188-228$ & 53.6 \\
\hline CS-16 & 1.57 & 1.97 & 1.00 & 0.60 & 0.37 & $167-209$ & 184.5 \\
\hline
\end{tabular}


into the femoral vein of the animals. Two dosage level ( 1 and $10 \mathrm{mg} \mathrm{kg}^{-1}$ ) tests were carried out for the two NaCS samples, with the $\mathrm{NaCS}$ solutions in physiological saline adjusted to $1 \mathrm{ml} \mathrm{kg}^{-1}$. Changes in respiration were measured by a respiration flow meter with tracheocanulation. The carotidal blood pressure was measured by the canulation of a pressure transducer to the carotid artery. The heart rate was measured from the wave pattern of the blood pressure and continuously recorded on a polygraph (San-ei Sokuki Co., Ltd., Japan).

Histamine Antagonist Pre-Treatment for

Blocking the Depression of Blood Pressure in

\section{Dog by NaCS Administration}

Diphenhydramine and atropine were used as histamine antagonists. Mepyramine, used as a histamine antagonist by Rothschild, ${ }^{13}$ is not considered sufficiently effective for blocking blood pressure depression induced by the liberation of histamine. ${ }^{16}$

A definite amount of diphenhydramine (5 $\mathrm{mg} \mathrm{kg}^{-1}$ ) was injected into the vein of the dogs, and after $2.7 \mathrm{~min}$, an additional 0.1 $\mathrm{mg} \mathrm{kg}^{-1}$ of atropine was injected. After the normal blood pressure recovered, histamine (0.01 $\left.\mathrm{mg} \mathrm{kg}^{-1}\right)$ or CS-4 $\left(10 \mathrm{mg} \mathrm{kg}^{-1}\right)$ was administered into the vein, and the blocking action of histamine antagonists was examined.

\section{RESULTS AND DISCUSSION}

Administration of $1 \mathrm{mg} \mathrm{kg}^{-1}$ of both CS-4 and CS-16 to the dogs had no influence on blood pressure, heart rate or respiration, although Rothschild ${ }^{13}$ reported that injection of $0.3 \mathrm{mg} \mathrm{kg}^{-1}$ of $\mathrm{NaCS}$ into a rat depressed the average blood pressure by $20-68 \mathrm{mmHg}$. The minimum value of dosage level for inducing the blood pressure depression was different from that in Rothschild's experiments. This may be due to differences in animal species or in molecular characteristics and purity of $\mathrm{NaCS}$ samples. Although the results from

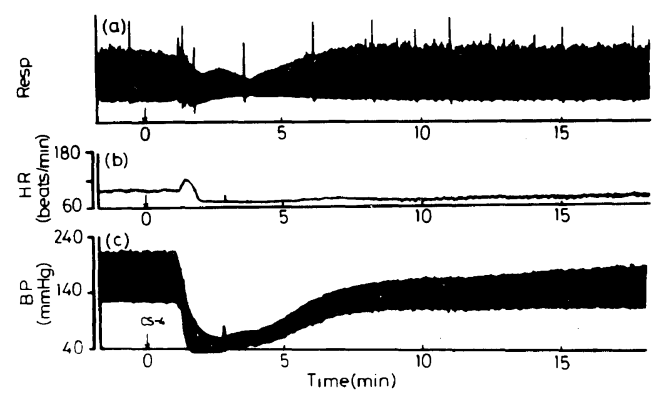

Figure 1. Changes in respiration (a), heart rate (b) and blood pressure (c) as a function of time elapsed after CS$4\left(10 \mathrm{mg} \mathrm{kg}^{-1}\right)$ administration to an anesthetized dog: Arrow mark denotes the time when CS-4 was injected.

animal tests do not apply to human beings, the $\mathrm{NaCS}$ samples used here may be useful as anticoagulant in blood dialysis for chronical renal insufficiency. Because 10000 IU of heparin is usually used for this purpose, only about $1 \mathrm{mg} \mathrm{kg}^{-1}$-human (average body weight: $60 \mathrm{~kg})$ of $\mathrm{NaCS} \quad(=185-220$ IU $\left.\mathrm{mg}^{-1}\right)$ is sufficient as an alternative for heparin. The dose value of $1 \mathrm{mg} \mathrm{kg}^{-1}$, which was found to have no effect on the cardiac function of dogs, may have no influence on that on human beings.

Figure 1 shows the changes in respiration (a), heart rate (b) and blood pressure (c) as a function of time following injection of CS-4 $\left(10 \mathrm{mg} \mathrm{kg}^{-1}\right)$. The arrow indicates the instance of $\mathrm{NaCS}$ administration. The average blood pressure abruptly decreased from 150 to 50 $\mathrm{mmHg}$, but in $3-4 \mathrm{~min}$ after the injection, the blood pressure began to resume its normal value. The difference between systolic and diastolic blood pressures also decreases from 90 to $30 \mathrm{mmHg}$ as a result of the injection, the pressure became normal within $30 \mathrm{~min}$ after the injection. The curve of recovering was similar to those reported for rats, ${ }^{13}$ but the time required was reduced by a half in our study. The heart rate increased in response to the abrupt blood pressure depression, readily decreased to $80 \%$ of the normal value, and then gradually recovered. However, heart rate recovery was significantly slower than that of 


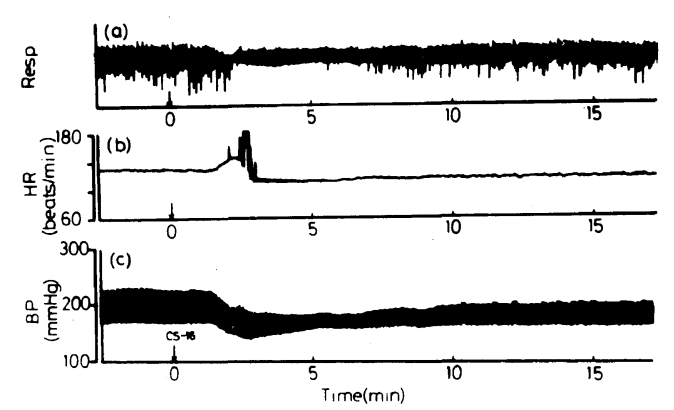

Figure 2. Changes in respiration (a), heart rate (b) and blood pressure (c) as a function of time elapsed after CS16 administration $\left(10 \mathrm{mg} \mathrm{kg}^{-1}\right)$ to an anesthetized dog: Symbols are the same as in Figure 1.

the blood pressure. The abrupt blood pressure depression was acompanied by a weaker and more frequent respiration, which regained its normal state in 7-8 min following injection.

Figure 2 shows the changes in respiration (a), heart rate (b) and blood pressure (c) as a function of time following injection of CS-16 $\left(10 \mathrm{mg} \mathrm{kg}^{-1}\right)$ to the dogs. The symbols in the figure are the same as in Figure 1. Both the normal blood pressure and heart rate of the dog used here were higher $(225-170 \mathrm{mmHg}$, $162 / \mathrm{min}$, respectively) than those for the dog used for CS-4. The average blood pressure gradually decreased from 197 to $157 \mathrm{mmHg}$ and then slowly became normal. The pulse pressure was minimum $6 \mathrm{~min}$ after the injection and continued to decrease during blood pressure recovery. The heart rate increased, then soon decreases to $75 \%$ of the normal value and finally returned to the normal value. A respiratory excitation was observed to persist for more than $30 \mathrm{~min}$.

Since different dogs were used for CS-4 and CS-16, a critical evaluation of the pharmacological activity of these two polymer samples must be made with reservation. The blood pressure depression, defined as the ratio of the maximum blood pressure depression to the normal average blood pressure, was 0.67 and 0.20 for CS- 4 and CS-16, respectively, indicating CS-4 to be 3.4 times higher that of CS-16. $\mathrm{LD}_{50}$ was 53.6 and 183.5 for CS-4 and CS-16,

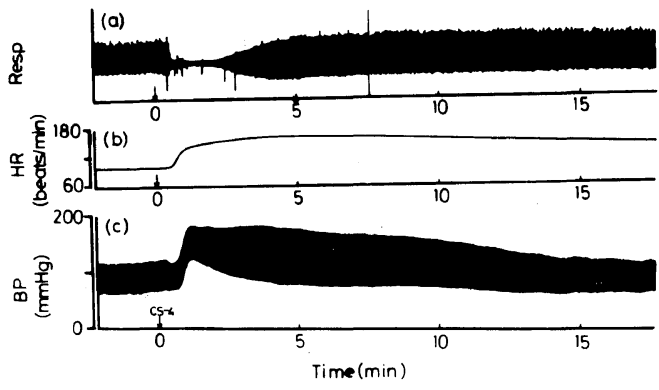

Figure 3. Changes in respiration (a), heart rate (b) and blood pressure (c) as a function of time elapsed after CS4 administration $\left(10 \mathrm{mg} \mathrm{kg}^{-1}\right)$ to an anesthetized cat: Symbols are the same as in Figure 1.

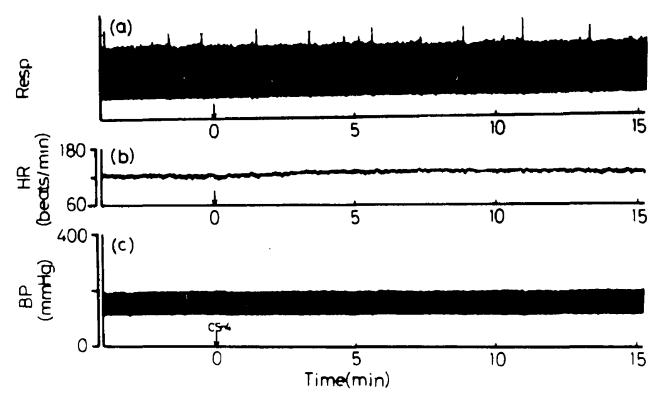

Figure 4. Effects of second administration of CS-4 (10 $\mathrm{mg} \mathrm{kg}^{-1}$ ) to an anesthetized dog on respiration (a), heart rate (b) and blood pressure.

respectively. Thus, the acute toxicity of CS-4 was again 3.4 times higher than that of CS-16. This similarity should be noted. As previously pointed out, ${ }^{10} \chi$ of $\mathrm{NaCS}$ is virtually a unique function of $\left\langle\left\langle\mathrm{f}_{2}\right\rangle+\left\langle\left\langle\mathrm{f}_{3}\right\rangle\right.\right.$, while $\mathrm{LD}_{50}$ is intricately influenced by $M_{n}$ and $\left\langle\mathrm{f}_{2}\right\rangle+\left\langle\mathrm{f}_{3}\right\rangle$. Thus, blood pressure depression may depend on both $M_{n}$ and $\left\langle\mathrm{f}_{2}\right\rangle+\left\langle\left\langle\mathrm{f}_{3}\right\rangle\right.$.

Figure 3 shows the results obtained for the injection of CS-4 $\left(10 \mathrm{mg} \mathrm{kg}^{-1}\right)$ into the cat. This administration significantly increased the blood pressure. The normal blood pressure $(115-60 \mathrm{mmHg})$ increased to $180-125$ $\mathrm{mmHg}$, but became normal $20 \mathrm{~min}$ after the injection. During this recovery pulse pressure became maximum (about $100 \mathrm{mmHg}$ ) 3 min after the injection. The heart rate also increased from 100 to $160 \mathrm{~min}^{-1}$ and required more than $30 \mathrm{~min}$ to become normal. The respiration amplitude greatly diminished and 
<smiles>NCCc1c[nH]cn1</smiles>

(a)

$$
\mathrm{CH}_{3} \mathrm{CO}_{2} \mathrm{CH}_{2} \mathrm{CH}_{2} \mathrm{~N}^{+}\left(\mathrm{CH}_{3}\right)_{3}
$$

(c)

Asp-Arg-Val-Tyr $\left\{\begin{array}{l}\text { Ile } \\ \text { all }\end{array}\right\}$-His-Pro-Phe

(e)
Arg-Pro-Pro-Gly-Ser

Arg-Phie-Pro

(b)<smiles>COC1=CC2C=CN=C(Cc3cccc(OC)c3OC)C2C=C1OC</smiles>

(d)

Figure 5. Chemical structures of the typical blood pressure depressing agents: a, histamine; b, bradykinin; c, acetylcholine; d, papaverine; e, angiotensin II.

its frequency increased. It is difficult to judge whether the difference in blood pressure change between dogs and cats was caused by the differences in animal species or individuality. Both an increase and decrease in blood pressure due to liberation of histamine were found for cat and rabbit. ${ }^{16}$

Blood pressure depression in the dog by CS4 was accompanied by tachyphylaxis. A second such administration caused no depression. In this case, neither heart rate nor respiration was influenced by the second dose, as evident from Figure 4. In general, tachyphylaxis arises from a lowered acceptor sensitivity toward the substance injected or from depletion of certain ortacoids which induce blood pressure depression. For example, some surfactants react with mast cells which associate with connective tissues throughout the body to liberate histamine, resulting in an abrupt blood pressure depression with tachyphylaxis. ${ }^{16,17}$

There are several known physiologically active substances which induce blood pressure depression, such as histamine, bradykinin, acetylcholine, papaverine and angiotensin. Their chemical structures are illustrated in
Figure 5. Serotonine, prostagrandin $\mathrm{I}_{2}, \mathrm{E}_{2}$ (both fatty acids consisting of twenty carbons), eledoisin (a kinin derivative), substance P (a kinin derivative), all either vasoconstrictor or vasodilator, have also been reported to cause blood pressure depression. However these substances are hardly present at all in body tissues. Histamine mainly exists in mast cells, associated with heparin or chondroitin sulfate. Its blood pressure depressive action consists in the dilatation of arteriols and the liberation of cathecholamines from adrenal medulla. Bradykinin and angiotensin are tissue hormones produced by the enzymatic degradation of plasma proteins. The former acts on smooth muscle, promotes capillary permeability and produces pain at a human skin blister base. Acetylcholine acts as a chemical mediator for the transport of impulses through the cholinergic nervous system, liberating between the motor end plate and plasma membrane. The quarternary amine structure of acetylcholine plays important role in its pharmacological activity. Blood pressure depressive activity is transient and blocked by atropine. Papaverine, a very potent coronary vasodilator, is a 

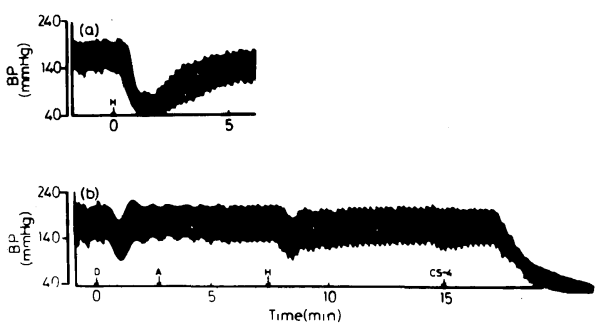

Figure 6(a). Effect of histamine administration (0.01 $\mathrm{mg} \mathrm{kg}^{-1}$ ) to an anesthetized dog on the systematic blood pressure.

Figure 6(b). Effect of CS-4 administration (10 $\left.\mathrm{mg} \mathrm{kg}^{-1}\right)$ after pretreatment of diphenhydramine $(5$ $\left.\mathrm{mg} \mathrm{kg}{ }^{-1}\right)$, atropine $\left(0.1 \mathrm{mg} \mathrm{kg}^{-1}\right)$ and histamine $(0.01$ $\mathrm{mg} \mathrm{kg}^{-1}$ ) to an anesthetized dog on blood pressure.

smooth muscle relaxant.

Histamine, acetylcholine and papaverine have tertially amines in their molecules. Hence, when they are liberated by $\mathrm{NaCS}$, they should be soon neutralized by strongly anionic $\mathrm{NaCS}$ and rendered incapable of physiological action. The liberation of these substances may not necessarily be responsible for blood pressure depression by $\mathrm{NaCS}$ administration, as confirmed by the data in Figure 6, which shows the effects of the pretreatment of histamine antagonists. Figure 6(a) shows that the venous injection of histamine $\left(0.01 \mathrm{mg} \mathrm{kg}^{-1}\right)$ to a dog generates a $110 \mathrm{mmHg}$ depression of average blood pressure. Figure 6(b) shows the blocking action of histamine antagonists against blood pressure depression induced by histamine injected later. Pre-injection of diphenhydramine $\left(5 \mathrm{mg} \mathrm{kg}^{-1}\right)$ and atropine $(0.1 \mathrm{mmHg})$ resulted in only $40 \mathrm{mmHg}$ of blood pressure depression when 0.01 $\mathrm{mg} \mathrm{kg}^{-1}$ of histamine was injected, demonstrating their considerable blocking effect. However, the pre-treatment of these antagonists did not block blood pressure depression induced by $\mathrm{NaCS}$ injection. This result ruled out the liberation of histamine and acetylcholine as the cause of the blood pressure depression by $\mathrm{NaCS}$ injection. It is also difficult to consider $\mathrm{NaCS}$ as having acetylcholine-like activity, since $\mathrm{NaCS}$ is anionic, thus differing from acetylcholine which is cationic. Considerations applying to acetylcholine may also apply to papaverine. There is another reason for ruling out the possibility that $\mathrm{NaCS}$ liberates papaverine or has papaverine-like action. Because papaverinelike action has typical nonspecific atony action on smooth muscle, the direction of the change in blood pressure induced by it should be independent of animal species. Thus, results obtained for the cat and dog in our study disprove the liberation of papaverine.

Two possibilities exist for blood pressure depression by $\mathrm{NaCS}$ administration: liberation of bradykinin or angiotensin. These substances are peptide hormones produced by enzymatic degradation of proteins. NaCS may perticipate in the above-mentioned process. It cannot be entirely denied that $\mathrm{NaCS}$ functions in the angiotensin producing process. However, bradykinin is probably the most probable cause for blood pressure depression. First, bradykinin is produced from a plasma protein with higher probability to encounter $\mathrm{NaCS}$ intraveneously injected. Second, bradykinin is a protein with arginines at its molecular ends, so that its liberation can be facilitated by NaCS. Third, the activity of bradykinin is said to be due to the serine and proline residues in its molecule, so that the ionic interaction between $\mathrm{NaCS}$ and bradykinin does not influence the action of the latter. Forth, while estimating $\mathrm{LD}_{50}$, rats very often showed signs of torture and excitation as a result of $\mathrm{NaCS}$ injection. This may be related to the liberation of pain-inducing substance, bradykinin. The mechanism for this liberation is not clear, but the kinin depletion from blood plasma of rat by $\mathrm{NaCS}$ administration demonstrated by Rothschild ${ }^{11}$ may occur in other animals such as dogs and cats.

The pharmacodynamic and pharmacological properties of polymeric drugs should bear a close relation to their molecular characteristics. This study, though of a very basic nature, 
has attempted to elucidate this point. A study carried out on a scale of much greater detail is highly desirable.

Acknowledgement. The authors should like to express their sincere appreciation to Mr. M. Mizuno and Mr. T. Sugihara of the Department of Development of Medical Supplies, Ashahi Chemical Industry Co., Ltd., for their kind assistance in evaluating the cardiac function of the animals.

\section{REFERENCES}

1. S. Bergstrom, Naturwissenschaften, 25, 706 (1935).

2. T. Astrup, I. Galsmar, and M. Volkert, Acta Physiol. Scand., 8, 215 (1944).

3. P. Karrer, H. Koenig, and E. Esteri, Helv. Chim. Acta, 26, 1296 (1943).

4. T. Astrup and J. Piper, Acta Physiol. Scand., 9, 351 (1945).
5. J. Piper, Acta Physiol. Scand., 9, 28 (1945).

6. J. Piper, "Farmakologiske Undersogelser over Syhtetiske Heparin-lignande Stoffer," (Disp.), Copenhagen, 1945.

7. G. Kindness, W. F. Long, and F. B. Williamson, Br. J. Pharm., 68, 645 (1980).

8. G. Kindness, W. F. Long, and F. B. Williamson, $B r$. J. Pharm., 69, 675 (1980).

9. W. F. Long, F. B. Williamson, G. Kindness, M. Edward, and J. H. Winter, Biochem. Soc., Transactions, 586th Meeting, Bristol, 1980, p 188.

10. K. Kamide, K. Okajima, T. Matsui, M. Ohnishi, and H. Kobayashi, Polym. J., 15, 300 (1983).

11. A. M. Rothschild and L. A. Gascon, Nature (London), 212, 1364 (1966).

12. A. M. Rothschild, Int. Symposium on Vaso-active Polypeptides: Bradykinin and Related Kinins, Vol. 197, Sao Paulo, 1967.

13. A. M. Rothschild, Br. Pharm. Chemother., 33, 501 (1968).

14. K. Kishino, T. Kawai, T. Nose, M. Saito, and K. Kamide, Eur. Polym. J., 17, 623 (1981).

15. K. Kamide and K. Okajima, Polym. J., 13, 127 (1981).

16. T. Tajima, Oyo Yakuri, 5, 489 (1971). 